\title{
Does Decision-making in End-of-life Care Differ Between Graduating Medical Students and Experienced Physicians?
}

\author{
ALEKSI ALMINOJA ${ }^{1 *}$, REETTA P. PIILI $^{1,2^{*}}$, HEIKKI HINKKA ${ }^{3}$, RIINA METSÄNOJA ${ }^{4}$, \\ OUTI HIRVONEN ${ }^{5}$, KRISTIINA TYYNELÄ-KORHONEN ${ }^{6}$, JAANA KALEVA-KEROLA ${ }^{7}$, \\ TIINA SAARTO $^{8}$, PIRKKO-LIISA I. KELLOKUMPU-LEHTINEN ${ }^{1,2}$ and JUHO T. LEHTO ${ }^{1,2}$ \\ ${ }^{1}$ Faculty of Medicine and Health Technology, Tampere University, Tampere, Finland; \\ ${ }^{2}$ Department of Oncology, Tampere University Hospital, Tampere, Finland; \\ ${ }^{3}$ Rehabilitation Center Apila (ret.), Kangasala, Finland; \\ ${ }^{4}$ Faculty of Social Sciences, Tampere University, Tampere, Finland; \\ ${ }^{5}$ Department of Oncology and Radiotherapy, Turku University Hospital, \\ and Department of Clinical Oncology, University of Turku, Turku, Finland; \\ ${ }^{6}$ Centre of Oncology, Kuopio University Hospital, Kuopio, Finland; \\ ${ }^{7}$ Department of Oncology, Mehiläinen Länsi-Pohja Ltd, Kemi, Finland; \\ ${ }^{8}$ Helsinki University Hospital, Comprehensive Cancer Center, \\ Department of Palliative Care and Faculty of Medicine, University of Helsinki, Helsinki, Finland
}

\begin{abstract}
Background/Aim: Appropriate decision-making in end-of-life (EOL) care is essential for both junior and senior physicians. The aim of this study was to compare the decisionmaking and attitudes of medical students with those of experienced general practitioners $(G P)$ regarding EOL-care. Materials and Methods: A questionnaire presenting three cancer patient scenarios concerning decisions and ethical aspects of EOL-care was offered to 500 Finnish GPs and 639 graduating medical students in 2015-2016. Results: Responses were received from 222 (47\%) GPs and 402 (63\%) students. The GPs withdrew antibiotics $(p<0.001)$ and nasogastric tubes $(p=0.007)$ and withheld resuscitation $(p<0.001)$, blood transfusions $(p=0.002)$ and pleural drainage $(p<0.001)$ more often than did the students. The students considered euthanasia and assisted suicide less reprehensible $(p<0.001$ in both) than did the GPs. Conclusion: Medical students were more unwilling to withhold and withdraw therapies in EOLcare than were the GPs, but the students considered
\end{abstract}

This article is freely accessible online.

*These Authors share the first authorship of this article.

Correspondence to: Reetta P. Piili, Department of Oncology, Tampere University Hospital, Teiskontie 35, R-building, 33520 Tampere, Finland. Tel: +358 331163161, e-mail: reetta.piili@tuni.fi

Key Words: Decision-making, end-of-life care, education, medical students, palliative care. euthanasia less reprehensible. Medical education should include aspects of decision-making in EOL-care.

There is a growing demand for palliative care in Europe due to the increase in noncommunicable diseases (1). Therefore, physicians should have basic skills needed to change the goal of the treatment from life-prolonging therapies to end-of-life (EOL)-care.

Appropriate decisions needed for high-quality EOL-care involve, for example, statements regarding cardiopulmonary resuscitation (CPR), hydration, and diagnostic tests. Many physician-related factors (e.g., age, experience and personal attitudes) have been shown to influence these decisions (2-4). In addition, the changing public attitudes towards EOL-care and euthanasia influence the complexity of these issues (5).

The physicians' decisions regarding life-sustaining treatments vary between different treatment modalities (6-8). In a survey of American internists, blood products and haemodialysis were among the most likely withdrawn therapies, while mechanical ventilation and intravenous fluids were more commonly continued (6). Withdrawing treatment is generally experienced as more difficult than withholding them (9).

The education and experience of a physician have been shown to influence decision-making in EOL-care $(8,10)$. Although newly-graduated physicians often feel unprepared for providing EOL-care, they face the complexity of the decision-making process just as the senior physicians (11, 12). However, the difference between graduating medical students and physicians in making these decisions remains to be studied. 
The aim of this study was to evaluate and compare the decision-making and attitudes of medical students and experienced GPs regarding several aspects of EOL-care of cancer patients. The results could be useful for the planning of medical education concerning decision-making in EOL-care.

\section{Materials and Methods}

Participants. In autumn 2015, a postal survey with a questionnaire was sent to 500 GPs who were randomly selected from the registry of the Finnish Medical Association [details published earlier by Piili et al. $(8,13)]$. The survey was sent twice to non-respondents. A questionnaire with the same hypothetical patient scenarios was offered to all Finnish medical students during their last year of medical school (Table I). All five universities with a faculty of medicine (Tampere, Helsinki, Turku, Kuopio and Oulu) participated in the study during the autumn of 2015 and the spring of 2016 depending on the graduation date at each university. The questionnaire was given to 639 students during a teaching session and returned to the teacher either personally or by post. Valid responses to the questionnaire were obtained from $402(63 \%)$ and $245(49 \%)$ of the students and GPs, respectively. After excluding GPs who had graduated less than five years ago, $222(47 \%)$ GPs were included in this study. This study was approved by the Regional Ethics Committee of Tampere University Hospital, Finland (R15101).

Questionnaire. The questionnaire included seven patient scenarios, of which three were used in this study. In addition, there were several questions concerning the attitudes and background factors of the respondents. Attitudes towards several ethical and personal aspects were assessed with a 100 -mm visual analogue scale (VAS) from "definitely agree" $(0 \mathrm{~mm})$ to "definitely disagree" $(100 \mathrm{~mm})$. These included, for example, statements concerning euthanasia, palliative care, the role of religion and advance directives in the decision-making process. The respondents were instructed to answer the questions in the given order and to not change their answers once given. This questionnaire has been previously used and validated among Finnish physicians (2-4).

Patient scenarios. Scenario 1: An 82-year-old forest worker was diagnosed with prostate cancer 3 years ago. During the past year, he has received treatments for bone metastases. He has now been hospitalized for a month, is almost totally bedridden, and needs help with all activities. His mental condition has been normal. His general condition has weakened during the past week to the point where he is now totally bedridden and is receiving large doses of pain medication. Today, he became comatose. His haemoglobin count is $68 \mathrm{~g} / 1$, while a week ago it was $118 \mathrm{~g} / \mathrm{l}$. His blood pressure is $80 / 40 \mathrm{mmHg}$. There is no verbal or written advance directive. The patient's wife has previously said that she expects the doctor to make all treatment decisions according to his/her best understanding. After the scenario, the doctors were asked to choose one of the given treatment options. The concepts used in the treatment options were explained as follows: a) palliative care: good nursing, sufficient medication for pain and other symptoms, and intravenous hydration only when suggested to provide relief of the patient's symptoms; b) active care: use of antibiotics and intravenous hydration or blood transfusions aimed at saving the patient's life in a life-threatening condition; c) intensive care: transfer of the patient to an intensive care unit (ICU).
Scenario 2: A 32-year-old female patient is brought by ambulance to the emergency unit. She is accompanied by her husband who says his wife has inoperable brain cancer. She has been receiving maximum radiotherapy, but this was discontinued three weeks ago. She has deteriorated considerably during the past week. The patient has now had an epileptic seizure and has been unconscious since the attack. After $20 \mathrm{~min}$ at the hospital, the patient stops breathing, and there is no pulse. Your treatment decision as a doctor on call is one of the following: a) to start cardiopulmonary resuscitation (CPR) or b) to withhold CPR.

Scenario 3: A 62-year-old male patient with lung cancer and metastases was admitted to the hospital ward and received highdose morphine medication. Due to respiratory weakening, he had become comatose the night before. He also suffered from severe anaemia and had abundant pleural effusion and fever. After the presentation of the patient scenario, there was a question about the treatment decision: Which of the following treatments already started $\left(^{*}\right)$ or planned would you withhold or withdraw? The decision responses were expressed on a scale from 1 (I definitely would not) to 5 (I definitely would). The treatments were a) antibiotics $(*)$; b) mechanical ventilation $(*)$; c) blood transfusion; d) pleural drainage; e) chest X-ray examination; f) laboratory tests; g) intravenous hydration $(*)$; h) nasogastric tube $(*)$; i) thrombosis prophylaxis $(*)$; and $\mathrm{j}$ ) supplementary oxygen $(*)$.

Statistical analysis. The answers were re-categorized dichotomously for the statistical analysis for the Scenarios 1 and 3 . The conversion was conducted as follows (responses shown in brackets): In the Scenario 1, "choosing palliative care" (a) and "not choosing palliative care" (b and c) and in the Scenario 3, "withhold or withdraw" (4 and 5) and "to not withhold or withdraw" (1,2 and 3 ). The comparison of the students and the GPs was performed using the Pearson Chi-Square test for the dichotomous variables (Figure 1 and Table II) and Mann-Whitney U test for the continuous variables (Table III). P-values less than 0.05 were accepted as statistically significant. The data analysis was performed using IBM SPSS Statistics for Windows, version 24.0.

\section{Results}

Characteristics of the participants are presented in Table I. All the students were under 50 years old, while over half of the GPs had reached this age. The GPs' median time from graduation was 23 years (range $=5-40$ years).

Treatment decisions in end-of-life care. The decisions of the students and GPs in patient scenarios 1 and 2 are shown in Figure 1. The GPs were more likely not to resuscitate the patient with an inoperable brain tumour (scenario 2), while the majority of both the students and the GPs chose the palliative care in the comatose patient with prostate cancer (scenario 1).

Willingness to withhold or withdraw therapies. The GPs were more likely to withdraw or withhold therapies than the students in a patient with an end-stage lung cancer (Table II). This difference was significant in withdrawing antibiotics and the nasogastric tube, and withholding blood transfusion, pleural drainage and taking a chest X-ray. 


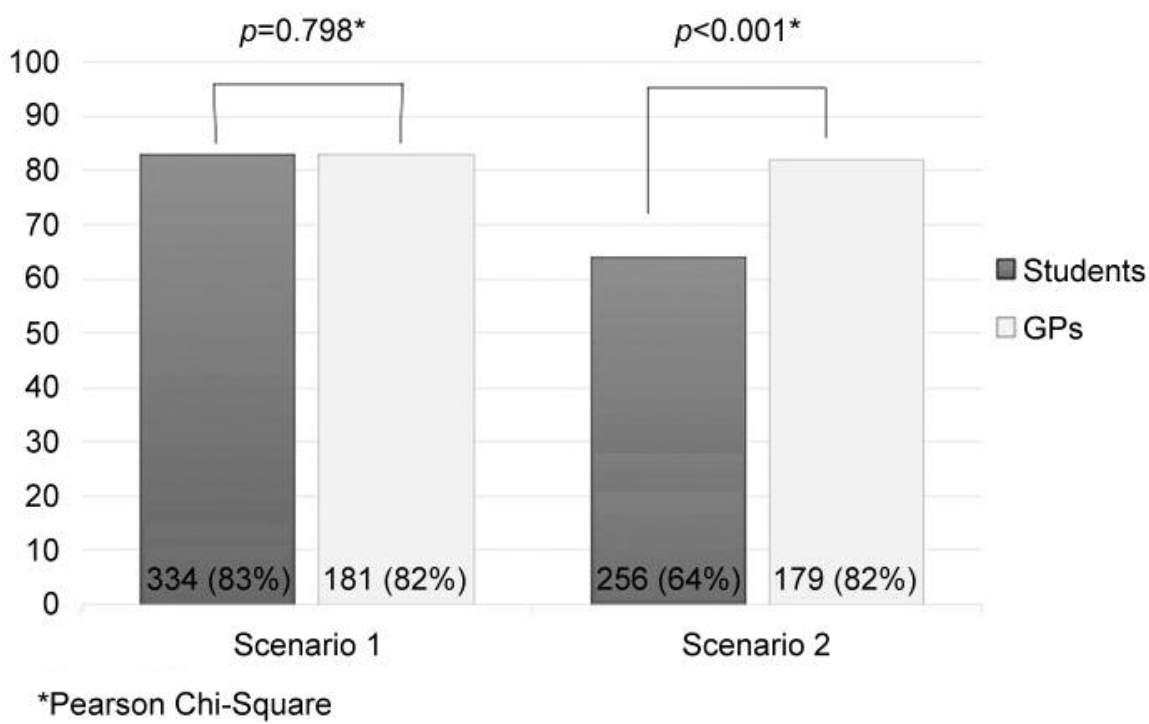

Figure 1. Proportions of students and general practitioners (GPs) choosing palliative-care approach for the comatose prostate cancer patient (scenario 1) and deciding not to resuscitate the patient with inoperable malignant brain tumour (scenario 2).

Attitudes. The students considered euthanasia and assisted suicide significantly less reprehensible than did the GPs $(p<0.001$ in both) as shown in Table III. Religion had a stronger influence on ethical decisions among the GPs than it did among the students. Most of the GPs and the students did not feel burn out, assessed their own health as excellent and achieved satisfaction from being a doctor.

\section{Discussion}

The graduating medical students were less willing to withdraw or withhold therapies such as resuscitation in EOLcare compared to experienced GPs. On the other hand, they considered euthanasia and assisted suicide less reprehensible than did the GPs.

In our study, the GPs were generally more willing to withdraw or withhold possible life-prolonging treatments than the medical students. Our results are in line with the study by Rivera and co-workers in which internal medicine faculty members accepted withholding or withdrawing lifesustaining therapy more often than the students (14). However, to our knowledge, there are no previous detailed surveys on medical students' opinions regarding lifeprolonging therapies during EOL-care.

According to our results, the GPs were more willing than the students to withhold blood transfusions, pleural drainage and chest $\mathrm{X}$-rays in a patient scenario representing EOLcare. The benefit of blood transfusions in EOL-care is often brief and adverse effects may occur (15). Dyspnoea can sometimes be alleviated by pleural drainage, but the
Table I. Characteristics of the participants.

\begin{tabular}{lcccc}
\hline & \multicolumn{2}{c}{ Students } & General practitioners \\
\hline Number & 402 & & 222 & \\
Response rate & $63 \%$ & & $47 \%$ & \\
Female, n (\%) & 248 & $(62 \%)$ & 157 & $(71 \%)$ \\
Age, median years (range) & 26 & $(23-46)$ & 51 & $(30-65)$ \\
Age distribution, n (\%) & & & & \\
$<25$ & 40 & $(10 \%)$ & 0 & $(0 \%)$ \\
$25-34$ & 347 & $(86 \%)$ & 26 & $(12 \%)$ \\
$35-49$ & 15 & $(4 \%)$ & 80 & $(36 \%)$ \\
$\geq 50$ & 0 & $(0 \%)$ & 116 & $(52 \%)$ \\
\hline
\end{tabular}

procedure is invasive (16). We suggest that the main reason that GPs are more willing to withhold these procedures is because they have experience on the risks and inconveniences of these interventions among frail patients. The GPs also withdrew antibiotics more frequently than the medical students. Antibiotics might occasionally be beneficial in EOL-care, but it is unclear whether students were aware of this or whether their decision was due to the difficulty in withdrawing therapies (17). Interestingly, the nasogastric tube was withdrawn more frequently by the GPs than the students, whereas there was no difference between the groups in withdrawing intravenous hydration. Neither intravenous hydration nor artificial feeding have been shown to improve survival or symptom control in EOL-care (1822). Almost half of the students and one third of GPs would 
Table II. Numbers and proportions of the students and the general practitioners (GPs) deciding to withdraw or withhold therapies in the scenario representing a patient with an end-stage lung cancer (scenario 3).

\begin{tabular}{|c|c|c|c|c|c|}
\hline & \multicolumn{2}{|c|}{ Students } & \multicolumn{2}{|c|}{ GPs } & \multirow[t]{2}{*}{$p$-Values* } \\
\hline & & & & & \\
\hline Antibiotics & 150 & $(37 \%)$ & 120 & $(55 \%)$ & $<0.001$ \\
\hline Mechanical ventilation & 300 & $(75 \%)$ & 176 & $(81 \%)$ & 0.095 \\
\hline Intravenous hydration & 128 & $(32 \%)$ & 75 & $(34 \%)$ & 0.543 \\
\hline Naso-gastric tube & 225 & $(56 \%)$ & 147 & $(67 \%)$ & 0.007 \\
\hline Thrombosis prophylaxis & 219 & $(55 \%)$ & 137 & $(63 \%)$ & 0.056 \\
\hline Supplementary oxygen & 18 & $(5 \%)$ & 13 & $(6 \%)$ & 0.440 \\
\hline \multicolumn{6}{|l|}{ Decision to withhold } \\
\hline Blood transfusion & 265 & $(67 \%)$ & 172 & $(79 \%)$ & 0.002 \\
\hline Pleural drainage & 84 & $(21 \%)$ & 92 & $(42 \%)$ & $<0.001$ \\
\hline Chest X-ray & 162 & $(41 \%)$ & 114 & $(52 \%)$ & 0.006 \\
\hline Laboratory tests & 178 & $(45 \%)$ & 114 & $(53 \%)$ & 0.060 \\
\hline
\end{tabular}

*Pearson Chi-Square test.

Table III. Attitudes of students and general practitioners (GPs).

\begin{tabular}{|c|c|c|c|c|c|}
\hline \multirow{2}{*}{ Attitudes, median VAS* (IQR) } & \multicolumn{2}{|c|}{ Students } & \multicolumn{2}{|c|}{ GPs } & \multirow[t]{2}{*}{$p$-Values** } \\
\hline & & & & & \\
\hline Active euthanasia is reprehensible & 58 & $(20-77)$ & 24 & $(3-66)$ & $<0.001$ \\
\hline Withdrawal of life-sustaining treatments is reprehensible & 93 & $(80-98)$ & 93 & $(77-98)$ & 0.588 \\
\hline Assisted suicide is reprehensible & 38 & $(10-69)$ & 10 & $(2-51)$ & $<0.001$ \\
\hline End-of-life care is satisfying & 26 & $(12-49)$ & 17 & $(3-36)$ & $<0.001$ \\
\hline People should pay costs of factitious diseases by themselves & 66 & $(40-84)$ & 76 & $(47-95)$ & $<0.001$ \\
\hline Advance directives have been helpful in my decisions & 14 & $(3-30)$ & 5 & $(2-22)$ & $<0.001$ \\
\hline Good palliative care enables good death & 4 & $(1-11)$ & 4 & $(1-10)$ & 0.372 \\
\hline Physicians can't estimate cancer pain & 46 & $(28-65)$ & 50 & $(28-72)$ & 0.053 \\
\hline Religion influences me when I make ethical decisions & 88 & $(50-98)$ & 74 & $(43-96)$ & 0.001 \\
\hline Being a doctor gives me satisfaction & 15 & $(4-28)$ & 8 & $(2-19)$ & $<0.001$ \\
\hline My health is excellent & 13 & $(6-25)$ & 14 & $(6-24)$ & 0.708 \\
\hline I feel burn out, tired of work & 85 & $(59-94)$ & 85 & $(66-95)$ & 0.250 \\
\hline I'm pleased with my salary & 13 & $(3-29)$ & 18 & $(7-45)$ & $<0.001$ \\
\hline It is a waste of resources to treat patients $>80$ years in ICU & 70 & $(50-85)$ & 78 & $(59-93)$ & 0.001 \\
\hline
\end{tabular}

*Attitudes expressed on a visual analogue scale (VAS) from $0 \mathrm{~mm}$ (definitely agree) to $100 \mathrm{~mm}$ (definitely disagree). **Mann-Whitney $U$-test. VAS: Visual analogue scale; IQR: interquartile range; ICU: intensive care unit.

not withdraw antithrombotic medication in EOL-care, although they are likely to be unbeneficial. Thus, these issues should be included in both undergraduate and postgraduate education in palliative medicine.

In a Brazilian study, $46 \%$ of medical students did not object to withdrawing artificial life support (23), while $75 \%$ of the medical students were willing to withdraw mechanical ventilation in our study. The variability among countries regarding the withdrawal of mechanical ventilation probably explains this difference (24). However, the students seem to comply with the practices of experienced physicians in Finland as $81 \%$ of the GPs also withdrew mechanical ventilation.
In our study, twice as many students $(36 \%)$ as GPs (18\%) were ready to attempt CPR on the patient with advanced brain tumour. Although advances in medicine may also benefit patients with very advanced diseases, the rate of hospital discharge after CPR for cancer patients is still only approximately $10 \%$ (25). Using this same patient scenario, we have previously demonstrated a correlation between younger age and attempted CPR among Finnish physicians (2). The growing clinical experience of a physician probably offers more insight into whether CPR may or may not be futile. On the other hand, over $80 \%$ of both the students and the GPs chose palliative care in a patient clearly approaching 
death (comatose patient with prostate cancer in scenario 1). Although the palliative care approach in this scenario could be regarded as obvious, our result shows that medical schools in Finland seem to offer a basic understanding of EOL-care.

In Western Europe, attitudes towards euthanasia and PAS have become more accepting among the public and, to a lesser extent, among physicians and medical students $(5,13$, $23,26)$. In our study, the students considered euthanasia and assisted suicide less reprehensible than the GPs. In a study from Puerto Rico, $40 \%$ of the medical students and $20 \%$ of members of the medical faculty accepted euthanasia (14), while only $26 \%$ of students and $17 \%$ of the physicians accepted euthanasia in a Polish study (27). Our results are not only in line with those of previous studies, but also highlight this difference in the changing atmosphere towards hastened death. We suggest, that the students' lack of clinical experience, younger age, as well as being less influenced by the impact of religion on their decisions may explain their greater acceptance of euthanasia as these factors have been associated with increased acceptance among the public and physicians $(5,13,28)$.

Our aim was not to affirm right or wrong answers to the questions presented, although some basic skills in decisionmaking during EOL-care were evaluated. Nevertheless, the majority of dying patients are taken care by GPs in Finland, and just graduated junior doctors are expected to work as a GP. Our results offer some insight into the educational needs, because the decision-making in EOL-care should include the same clinical principles for every patient regardless of the experience of a physician. Medical students have been found to feel underprepared to have discussions about EOL-care with a patient $(11,12,29)$. Furthermore, their knowledge about assisted dying, DNR orders, advance directives and many aspects of palliative medicine is still known to be inadequate (30-33). On the other hand, undergraduate curricula in palliative medicine increases students' knowledge on palliative care $(34,35)$ and their attitudes towards EOL-care change after an observational experience in hospice (36). This calls for well-planned educational programmes in palliative medicine in every medical school and continuous postgraduate education. The medical and ethical principles of the complex decision-making in the EOL-care are the cornerstones of this education.

Some limitations of our study must be acknowledged. The response rates $(63 \%$ for the students and $47 \%$ for the GPs) limits the generalizability of our results, though they are higher than in many previous surveys of physicians (37). Our survey presenting hypothetical patient scenarios may also elicit different answers compared to the decisions made in clinical practice. However, it would be difficult to study these questions in a real-life setting and we suggest that the answers do reflect the general tendencies that contribute to decision-making. Finally, the GPs are a heterogenous group of physicians, which might lessen the comparability between the GPs and the students. To improve the validity of this comparison, we included only experienced GPs.

\section{Conclusion}

GPs are more willing to withhold or withdraw therapies suspected of being futile in EOL-care than graduating students, although this difference varies between the treatments. In contrast, students consider euthanasia less reprehensible than do the GPs. Our results call for systematic undergraduate and postgraduate education in palliative medicine, including the medical and ethical aspects of decision-making in EOL-care.

\section{Conflicts of Interest}

The Authors declare no conflicts of interest regarding this study.

\section{Authors' Contributions}

RP, PLKL, HH and JL designed the study outline and the questionnaire. RP, OH, KTK, JKK, TS, PLKL and JL collected the data. AA, RP, PLKL, JL and RM analysed the data. AA, RP and RM did the final statistical analysis. All the Authors contributed to the writing and reviewing of the manuscript and approved the final manuscript.

\section{Acknowledgements}

Funding: This study was funded by the Seppo Nieminen Legacy Fund, the Signe and Ane Gyllenberg Foundation, the Finnish Medical Association and the Cancer Society of Pirkanmaa. The funders did not have any role in the design of the study, in the collection, analysis or interpretation of the data; or in the writing of the manuscript.

\section{References}

1 Connor SR BM: Global atlas of palliative care at the end of life. 2014. Available at: http://www.who.int/ncds/management/ palliative-care/palliative-care-atlas/en/. Accessed Jun 2018.

2 Hinkka H, Kosunen E, Metsanoja R, Lammi UK and Kellokumpu-Lehtinen P: To resuscitate or not: a dilemma in terminal cancer care. Resuscitation 49(3): 289-297, 2001. PMID: 11719124.

3 Hinkka H, Kosunen E, Lammi EK, Metsanoja R, Puustelli A and Kellokumpu-Lehtinen P: Decision making in terminal care: a survey of finnish doctors' treatment decisions in end-of-life scenarios involving a terminal cancer and a terminal dementia patient. Palliat Med 16(3): 195-204, 2002. PMID: 12046995. DOI: 10.1191/0269216302pm510oa

4 Hinkka H, Kosunen E, Metsanoja R, Lammi UK and Kellokumpu-Lehtinen P: Factors affecting physicians' decisions to forgo life-sustaining treatments in terminal care. J Med Ethics 28(2): 109-114, 2002. PMID: 11934941. 
5 Emanuel EJ, Onwuteaka-Philipsen BD, Urwin JW and Cohen J: Attitudes and practices of euthanasia and physician-assisted suicide in the United States, Canada, and Europe. JAMA 316(1): 79-90, 2016. PMID: 27380345. DOI: 10.1001/jama.2016.8499

6 Christakis NA and Asch DA: Biases in how physicians choose to withdraw life support. Lancet 342(8872): 642-646, 1993. PMID: 8103146.

7 Hynninen M, Klepstad P, Petersson J, Skram U and Tallgren M: Process of foregoing life-sustaining treatment: A survey among Scandinavian intensivists. Acta Anaesthesiol Scand 52(8): 10811085, 2008. PMID: 18840108. DOI: 10.1111/j.1399-6576.2008. 01636.x

8 Piili RP, Lehto JT, Luukkaala T, Hinkka H and KellokumpuLehtinen PI: Does special education in palliative medicine make a difference in end-of-life decision-making? BMC Palliat Care 17(1): 94, 2018. PMID: 30021586. DOI: 10.1186/s12904-018-0349-6

9 Chung GS, Yoon JD, Rasinski KA and Curlin FA: US Physicians' Opinions about Distinctions between Withdrawing and Withholding Life-Sustaining Treatment. J Relig Health 55(5): 1596-1606, 2016. PMID: 26725047. DOI: 10.1007/ s10943-015-0171-x

10 Centeno $\mathrm{C}$ and Rodriguez-Nunez A: The contribution of undergraduate palliative care education: Does it influence the clinical patient's care? Curr Opin Support Palliat Care 9(4): 375391, 2015. PMID: 26418527. DOI: 10.1097/SPC.0000 00000 0000169

11 Aggarwal AR and Khan I: Medical students' experiences of resuscitation and discussions surrounding resuscitation status. Adv Med Educ Pract 9: 31-37, 2018 PMID: 29391840. DOI: 10.2147/AMEP.S141436.

12 Mills LM, Rhoads C and Curtis JR: Medical student training on code status discussions: How far have we come? J Palliat Med 19(3): 323-325, 2016. PMID: 26587872. DOI: 10.1089/ jpm.2015.0125

13 Piili RP, Metsanoja R, Hinkka H, Kellokumpu-Lehtinen PI and Lehto JT: Changes in attitudes towards hastened death among Finnish physicians over the past sixteen years. BMC Med Ethics 19(1): 40, 2018. PMID: 29843682. DOI: 10.1186/s12910-0180290-5

14 Ramirez Rivera J, Rodriguez $\mathrm{R}$ and Otero Igaravidez $\mathrm{Y}$ : Attitudes toward euthanasia, assisted suicide and termination of life-sustaining treatment of Puerto Rican medical students, medical residents, and faculty. Bol Asoc Med P R 92(1-3): 1821, 2000. PMID: 10846284.

15 Uceda Torres ME, Rodriguez Rodriguez JN, Sanchez Ramos JL and Alvarado Gomez F: Transfusion in palliative cancer patients: a review of the literature. J Palliat Med 17(1): 88-104, 2014. PMID: 24325560. DOI: 10.1089/jpm.2013.0387

16 Strasser F, Blum D and Bueche D: Invasive palliative interventions: when are they worth it and when are they not? Cancer J 16(5): 483-487, 2010. PMID: 20890144. DOI: 10.1097/ PPO.0b013e3181f842b3

17 Helde-Frankling $\mathrm{M}$, Bergqvist $\mathrm{J}$, Bergman $\mathrm{P}$ and BjorkhemBergman L: Antibiotic treatment in end-of-life cancer patientsa retrospective observational study at a palliative care center in Sweden. Cancers (Basel) 8(9): 84, 2016. PMID: 27608043. DOI: $10.3390 /$ cancers 8090084

18 Finucane TE, Christmas $\mathrm{C}$ and Travis $\mathrm{K}$ : Tube feeding in patients with advanced dementia: a review of the evidence. JAMA 282(14): 1365-1370, 1999. PMID: 10527184
19 Good P, Richard R, Syrmis W, Jenkins-Marsh S and Stephens J: Medically assisted hydration for adult palliative care patients. Cochrane Database Syst Rev (4): CD006273, 2014. PMID: 24760678. DOI: 10.1002/14651858.CD006273.pub3

20 Bruera E, Hui D, Dalal S, Torres-Vigil I, Trumble J, Roosth J, Krauter S, Strickland C, Unger K, Palmer JL, Allo J, FrisbeeHume $\mathrm{S}$ and Tarleton K: Parenteral hydration in patients with advanced cancer: a multicenter, double-blind, placebo-controlled randomized trial. J Clin Oncol 31(1): 111-118, 2013. PMID: 23169523. DOI: $10.1200 / \mathrm{JCO} .2012 .44 .6518$

21 Goldberg LS and Altman KW: The role of gastrostomy tube placement in advanced dementia with dysphagia: a critical review. Clin Interv Aging 9: 1733-1739, 2014. PMID: 25342891. DOI: $10.2147 /$ CIA.S53153

22 Good P, Richard R, Syrmis W, Jenkins-Marsh S and Stephens J: Medically assisted nutrition for adult palliative care patients. Cochrane Database Syst Rev (4): CD006274, 2014. PMID: 24760679. DOI: 10.1002/14651858.CD006274.pub3

23 Lucchetti G, de Oliveira LR, Leite JR, Lucchetti AL and SBRAME Collaborators: Medical students and controversial ethical issues: results from the multicenter study SBRAME. BMC Med Ethics 15: 85, 2014. PMID: 25511565. DOI: 10.1186/1472-6939-15-85

24 Lobo SM, De Simoni FHB, Jakob SM, Estella A, Vadi S, Bluethgen A, Martin-Loeches I, Sakr Y, Vincent JL and ICON investigators: Decision-making on withholding or withdrawing life support in the ICU: A worldwide perspective. Chest 152(2): 321-329, 2017. PMID: 28483610. DOI: 10.1016/j.chest.2017. 04.176

25 Miller AH, Sandoval M, Wattana M, Page VD and Todd KH: Cardiopulmonary resuscitation outcomes in a cancer center emergency department. Springerplus 4: 106, 2015. PMID: 25793149. DOI: $10.1186 / \mathrm{s} 40064-015-0884-z$

26 Stronegger WJ, Schmolzer C, Rasky E and Freidl W: Changing attitudes towards euthanasia among medical students in Austria. J Med Ethics 37(4): 227-229, 2011. PMID: 21126965. DOI: 10.1136/jme.2010.039792

27 Leppert W, Majkowicz M and Forycka M: Attitudes of Polish physicians and medical students toward breaking bad news, euthanasia and morphine administration in cancer patients. J Cancer Educ 28(4): 603-610, 2013. PMID: 24170311. DOI: 10.1007/s13187-013-0553-2

28 Lofmark R, Nilstun T, Cartwright C, Fischer S, van der Heide A, Mortier F, Norup M, Simonato L, Onwuteaka-Philipsen BD and EURELD Consortium: Physicians' experiences with end-oflife decision-making: survey in 6 European countries and Australia. BMC Med Feb 6: 4, 2008. PMID: 18269735. DOI: 10.1186/1741-7015-6-4

29 Romotzky V, Galushko M, Dusterdiek A, Obliers R, Albus C, Ostgathe C and Voltz R: "It's not that easy"--medical students' fears and barriers in end-of-life communication. J Cancer Educ 30(2): 333-339, 2015. PMID: 25113025. DOI: 10.1007/s13187014-0712-0

30 Anneser J, Jox RJ, Thurn T and Borasio GD: Physician-assisted suicide, euthanasia and palliative sedation: attitudes and knowledge of medical students. GMS J Med Educ 33(1): Doc11, 2016. PMID: 26958648. DOI: 10.3205/zma001010

31 Hesselink BA, Pasman HR, van der Wal G, Soethout MB and Onwuteaka-Philipsen BD: Education on end-of-life care in the medical curriculum: students' opinions and knowledge. J Palliat 
Med 13(4): 381-387, 2010. PMID: 20144023. DOI: 10.1089/ jpm.2009.0291

32 Mirarchi FL, Ray M, Cooney T and TRIAD IV: Nationwide Survey of medical students' understanding of living Wills and DNR orders. J Patient Saf 12(4): 190-196, 2016. PMID: 24583955. DOI: 10.1097/PTS.0000000000000083

33 Rumpold T, Lutgendorf-Caucig C, Loffler-Stastka H, RoiderSchur S, Potter R and Kirchheiner K: Attitude towards end of life communication of Austrian medical students. J Cancer Educ 23, 2018. PMID: 29687186. DOI: 10.1007/s13187-018-1366-0

34 Lehto JT, Hakkarainen K, Kellokumpu-Lehtinen PL and Saarto $\mathrm{T}$ : Undergraduate curriculum in palliative medicine at Tampere University increases students' knowledge. BMC Palliat Care 16(1): 13, 2017. PMID: 28122553. DOI: 10.1186/s12904-016$0182-8$
35 Parikh PP, White MT, Buckingham L and Tchorz KM: Evaluation of palliative care training and skills retention by medical students. J Surg Res 211: 172-177, 2017. PMID: 28501114. DOI: $10.1016 /$ j.jss.2016.11.006

36 Wechter E, O'Gorman DC, Singh MK, Spanos P and Daly BJ: The effects of an early observational experience on medical students' attitudes toward end-of-life care. Am J Hosp Palliat Care 32(1): 52-60, 2015. PMID: 24198062. DOI: $10.1177 / 1049909113505760$

37 Asch DA, Jedrziewski MK and Christakis NA: Response rates to mail surveys published in medical journals. J Clin Epidemiol 50(10): 1129-1136, 1997. PMID: 9368521.

Received March 7, 2019 Revised April 11, 2019 Accepted April 12, 2019 